\title{
Applied Basic Courses under the Background of Mathematical Modeling Idea into Mathematics Teaching in the Discussion
}

\author{
Yanying $\mathrm{Ma}^{1}$, Xiuzhen $\mathrm{Li}^{1, \mathrm{a}^{*}}$, Chao $\mathrm{Ma}^{2}$ and Xin Wang ${ }^{3}$ \\ ${ }^{1}$ Jilin Engineering Normal University .Changchun; China; \\ ${ }^{2}$ China Petroleum Northern Engineering CO,LTD . Jilin ; China; \\ ${ }^{3}$ Shenyang Jianzhu University. Shenyang, China \\ aluozhangyulong@163.com \\ * corresponding author: Xiuzhen Li
}

Keywords: Mathematical modeling; Mathematics teaching; Applied

\begin{abstract}
At present, the applied undergraduate colleges students' motivation to learn higher mathematics is not enough, did not form a good habit of higher mathematics learning, teacher's teaching method is drab, cannot effectively organize the teaching activities based on students' knowledge and ability level. Applied undergraduate colleges and universities of higher mathematics teaching reform should be to select and organize the teaching content carefully, reform the teaching mode, change the proportion of grades, increase the proportion of procedural learning, diversified teaching evaluation system reform. Under the background of the article in view of the practical common problem in college mathematics teaching, analyzes the mathematical modeling idea into mathematics the important role of basic course teaching, and in view of the mathematical modeling thought into university mathematics teaching method are discussed in this paper, for the reform of university mathematics method.

In today's rapid development of science and technology, mathematics has infiltrated the social various fields, especially under the background of transformation applied to the quality of the mathematics of the high-quality practical talents requirement also gradually improve, it puts forward higher requirements on college mathematics teaching. The university mathematics teaching in colleges and universities does not keep pace with The Times, most of the talent training will only mathematical problem solving, rather than the application of mathematical knowledge to the practice, such ability obviously not suitable for practical background of the need of social development. Mathematical foundation course for students to learn professional courses and other mathematics courses lay a necessary mathematical foundation, in cultivating applied talents and improving math ability and mathematics quality has an irreplaceable role to other courses. Therefore, it is necessary to integrate mathematical modeling ideas into the basic curriculum of university mathematics, which meets the needs of social development and the reform of education in university mathematics.
\end{abstract}

\section{Teaching status of basic courses of university mathematics}

Most of the college mathematics courses teaching content is almost a step-by-step, fixed, single teaching means and teaching methods, teaching mode, students passively accept theory knowledge, and the lack of practical ability. In the content of teaching, teacher retheory, light application. In the course system, teachers only attach importance to the independent integrity of each course and neglect the links between the subjects, and lack the contact with the specialized courses. On the teaching method, is given priority to with "injection", teachers teach and students to accept, the lack of communication between teachers and students is not conducive to cultivate students' self-study ability and application ability, is not conducive to develop students' innovative thinking. The teaching method is single, most mathematics teachers still use "chalk + blackboard" the way to teach, the knowledge information that teaches is very limited. On the application of mathematics, almost all of the books are still in the classical geometry on the application and the application of classical physics, the basic no, introduces the application of mathematics in the modern engineering theory and the practice come apart seriously, 
causes students don't know this professional learning math do you have any help, not to mention learning interest in mathematics, but also not conducive to the learning of students the follow-up professional courses. Mathematical modeling in higher mathematics teaching into the insufficient. Although in the mathematics basic course with some mathematical modeling method and the interpretation of examples, or leave some mathematical modeling case lets the student group or complete after class. But because only one partition of the basic courses of mathematics modeling method tell me a little time on and did not form a long-term system of the teaching system, to improve the students' ability of the effect is not significant, therefore in mathematics foundation course teaching mode and the arrangement of the content to make reasonable adjustment and teaching material design, increase the intensity of mathematical modeling thought into, improve the students' ability to analyze and solve problems.

\section{Mathematical modeling}

Mathematical modeling is a mathematical application that USES mathematical models to solve practical problems, and relates "mathematical knowledge, methods" to "practical problem solving". When practical problems are not solved directly, some ready-made mathematical knowledge and methods can be used to solve the problem of mathematical problems. Or the origin of the problem. Especially in the applied background, focus on training applied undergraduate talents analysis problem solving skills, in the mathematics basic course teaching vigorously cultivate students into the actual problem consciousness and the ability of mathematical problems. Because the calculation and analysis of mathematical problem requires students to master relevant knowledge of mathematics, and a simple mathematical knowledge tend to be more abstract, in math class is less applied undergraduate colleges and universities students, is not easy to accept, this will need to convert it to the student in the teaching of interest to the actual problem, through the actual background to help students to understand. Let students learn the application in learning knowledge, learn knowledge in application, promote the coordinated development of students' knowledge, ability and quality, and promote the cultivation of applied undergraduate talents.

\section{The mathematical modeling thought into mathematical foundation course of the discussion}

The mathematical modeling thought and the combination of higher mathematics course. Higher mathematics is at the university of engineering is an important professional basic course. Traditional mathematics teaching focus on the use of problem solving method and skill, so education of the students only know mathematical problem solving, and don't know how to use mathematics. Teachers should appropriate mathematical modeling ideas in teaching content, introduce the background and the application of concepts and theorem, this is to make the students feel the fun of math, and to improve student's mathematics application ability.

For example: speak micro element method, can introduce interpersonal ।"roll with the punches, consequencel" of the application. Students fully experience the things life has to do with mathematics.

In the interpretation of the divergence of infinite series, can through the interpretation of the story into three series: arithmetic progression, geometric series, harmonic progression, suppose a philanthropists want to support a child, if children can infinite time with him for money, have the following three ways:

Every time to 0.1 yuan, $0.1+0.1+0.1+\ldots$;

To 100 yuan for the first time, the second half to 100 yuan, after successive in half, a quarter $+1 / 2$ $+100+100 * 100 * \ldots$;

To 1 yuan for the first time, every time to the amount of money is given to the reciprocal of the number of times, $1+1 / 2+1 / 3+\ldots$;

Do you want to do what kind of philanthropist? So that students will be very interested in this problem, can undertake group discussions, arouse the enthusiasm of students' learning. 
The combination of mathematical modeling thought and linear algebra course. At present, a lot of linear algebra teaching on theoretical knowledge is given priority to, rarely involves the practical application. In linear algebra teaching, the teacher can choose simple, intuitive knowledge and the corresponding mathematical modeling case, in order to improve student's mathematics application ability. According to different professional, can choose different instances. In information engineering, for example, students can speak some more cases of information coding.

The mathematical modeling thought and the combination of probability and mathematical statistics course. Probability and mathematical statistics courses are common in the application of life. Can speak, for example, random events and probability, by simple dice and flip a coin problem expands to winning the lottery of life; Speak full probability formula and bayes formula, can introduce ।"by for fruit" and ।"by the fruit known as $\ "$ problem. In the teaching of probability and statistics in mathematical modeling thought, can let the student to utilize the knowledge in analysis of random phenomena around, to improve student's mathematics application ability and innovation ability.

\section{Discussion}

The transformation of the applied background, the basic math goal is to make students in the master the mathematical theory and methods on the basis of cultivating the innovative thinking and the application ability of theoretical knowledge. Mathematical modeling is to use mathematical tools and mathematical thought the practice process of solving practical problems, can help students familiar with mathematical thought and method, realize mathematics play a great role in solving practical problems, to cultivate students creativity and practical ability. Therefore in mathematics into mathematical modeling ideas in basic course teaching, not only play an important role for promoting the university mathematics teaching reform, and applied in the context of inter-disciplinary talent of education high quality also has the profound significance.

\section{Acknowledgements}

This research was supported by the research and practice of mathe- matical modeling thinking in the teaching of mathematics basic course teaching in the scientific planning project of jilin province in 2017(No.GH170637), the teaching mode of higher mathematics in the context of "Internet plus" (No.201622) and the Support Foundation of Shenyang Jianzhu University (No.2017034) respectively.

\section{References}

[1] Daqian Li. Mathematical modeling idea into mathematics class backbone course [J]. Journal of China university mathematics, 2006 (1).

[2] Xia Shi. On the thinking of developing inquiry learning in mathematics modeling teaching [J]. Journal of education and profession, 2010 (12).

[3] Luo Yuan Zheng Kelong. Mathematical modeling thought and the combination of engineering mathematics teaching study [J]. Journal of higher education research, 2011 (4).

[4] Shu-zhong Wang, on record, dong-yan Chen. Mathematical modeling and engineering exploration and practice of mathematics teaching reform [J]. Journal of heilongjiang province higher education research, 2005 (10).

[5] Su WeiJun. The role of mathematical modeling activities to cultivate talented person [J]. Journal of mathematics practice and understanding, 2002 (5).

[6] Mark Chan, Huang Yong, hui-min jiang etc. Mathematical modeling and quality education [J]. Journal of mathematics practice and understanding, 2003 (2).

[7] Song Yunyan, Zhu Wenxin. Analyses the university mathematics teaching of mathematical modeling thought into the [J]. Journal of education and profession, 2015 (4).

[8] $\mathrm{Xu}$ Maoliang. Permeating mathematical modeling ideas in traditional math class [J]. Journal of mathematics practice and understanding, 2003 (4). 
[9] Wei Chengdong, etc. In the ordinary differential equation into the exploration and practice of mathematical modeling ideas in teaching $[\mathrm{J}]$. Journal of mathematics practice and understanding, 2008 (20).

[10] Han Zhonggeng. Introduction to mathematical modeling and the cultivation of the talent [J]. Journal of engineering mathematics, 2003, (8) : 119-123.

[11] Fu Jun, Zhu Hong, Xian-changWang. In the practice of mathematical modeling teaching in training students' innovative ability and thinking [J]. Journal of mathematics education, 2007, (4) : 93-95.

[12] Xia Bing, Su-ying Bai, Shu-ping Pang, etc. To bring into full play the leading role of mathematical modeling in the high number of teaching [J]. Journal of financial theory and the teaching, 2009 (4).

[13] Sha Yuanxia. Based on the mathematical modeling of applied talents training [J]. Journal of changchun normal college, 2012, (9) : 112-114.

[14] He Junjie, Wang Juan. Into the mathematical modeling in higher mathematics teaching thought research [J]. Journal of contemporary education theory and practice, 2013 (12).

[15] Ma Ge, Du Yuepeng. The modern education technology environment of higher mathematics teaching reform practice and thinking [J]. Journal of higher mathematics research, 2004 (3).

[16]Feng Juan. Would mind mathematical modeling into the teaching of mathematics in [J]. Journal of education science, 2010 (8). 